\title{
Expansão da cultura de soja, infraestrutura viária e desenvolvimento regional: a BR 158 e o Vale do Araguaia Mato-Grossense entre 1990 e 2010
}

Margot Riemann Costa e Silva

Programa de Pós-Graduação em Desenvolvimento e Planejamento Territorial da Pontifícia Universidade Católica de Goiás (Puc/Goiás)

Carlos Leão

Programa de Pós-Graduação em Desenvolvimento e Planejamento Territorial da Pontifícia Universidade Católica de Goiás (Puc/Goiás)

Rosenilda Maria de Morais Silva

Mestranda do Programa de Pós-Graduação em Desenvolvimento e Planejamento Territorial da Pontifícia Universidade Católica de Goiás (Puc/Goiás)

Aline dos Santos Sousa

Mestranda do Programa de Pós-Graduação em Desenvolvimento e Planejamento Territorial da Pontifícia Universidade Católica de Goiás (Puc/Goiás)

Recebido: 23/11/2015 Versão revisada (entregue): 20/02/2016 Aprovado: 29/02/2016

\begin{abstract}
Resumo
O presente artigo relata pesquisa de indicadores de desenvolvimento regional no Vale do Araguaia Mato-grossense, a mesorregião Nordeste Mato-grossense, considerando o período de 1990 e 2010. A região é cortada pela BR 158, atualmente, um dos principais vetores da acelerada expansão do cultivo de soja para o interior do bioma amazônico. O forte avanço da produção de soja repercutiu em crescimento econômico acima das médias do estado do Mato Grosso e, também, do país. Entretanto, chama-se atenção para o fato de que os indicadores produtivos e sociais não acompanharam este movimento: as taxas de pobreza seguiram elevadas, aumentou o descompasso entre os diferentes setores produtivos (com forte retração da indústria) e se manteve significativa a defasagem da em relação às médias estaduais e nacionais em todos os estratos.
\end{abstract}

Palavras-chave | Cultura da soja; desenvolvimento regional; indicadores sociais; infraestrutura; Mato Grosso.

Código JEL | O13; O18; Q13. 


\title{
SOYBEAN CROP EXPANSION, ROAD INFRASTRUCTURE AND REGIONAL DEVELOPMENT: THE BR 158 AND THE NORTHEAST REGION OF MATO GROSSO (BRAZIL) FROM 1990 TO 2010
}

\begin{abstract}
The study reports on regional development indicators in the Mato Grosso Northeast from 1990 to 2015. The region is cross over by the BR 158, a highway that easies the expansion of soybean plantations deep into the amazon biome. Evidence was gathered that the strong advance of soybean production in this specific regional produces economic growth above average of Mato Grosso and Brazil, but social indicators were not found to be positive. Poverty rates continue high, the gap among different productive sectors increased, with significant downturn of the industry, and the gap between regional and national per capita household income increased.
\end{abstract}

Keywords | Infrastructure; Mato Grosso; regional development; social indicators; soybean.

JEL-Code | O13; O18; Q13.

\section{EXPANSIÓN DEL CULTIVO DE SOJA, INFRAESTRUCTURA VIAL Y DESARROLLO REGIONAL: LA BR 158 Y EL VALE DO ARAGUAIA MATO- GROSSENSE (BRASIL) ENTRE 1990 Y 2010}

\section{Resumen}

El artículo examina indicadores de desarrollo regional en el Vale do Araguaia Mato-grossense, la región Nordeste Mato-grossense, entre 1990 y 2010. La región es cortada por la BR 158, la carretera que ha sido uno de los más importantes vectores de expansión del cultivo de soja en dirección al interior del bioma amazónico. El fuerte avance de la producción de granos repercutió en el crecimiento económico superior a la media del estado de Mato Grosso y del Brasil. Entretanto, llama la atención el hecho de que las tasas de pobreza continuaron altas, hubo aumento de la brecha entre los diferentes sectores productivos (con fuerte retracción de la industria), y se ha mantuvo ampliada la discrepancia en el ingreso domiciliar per cápita en comparación con los promedios nacionales en todos los estratos.

Palabras-clave | Cultivo de soja; desarrollo regional; indicadores sociales; infraestructura; Mato Grosso.

Código JEL | O13; O18; Q13.

\section{Introdução}

O Brasil é na atualidade o maior exportador de soja no mundo, com 68.977.953 toneladas na estimativa de 2015, sendo o estado do Mato Grosso o maior produtor nacional (27.766.988 toneladas), segundo dados de 2015 da Federação de Indústrias do Estado de São Paulo, FIESP. Depois de dominar o bioma cerrado, movimento em contínua progressão desde a década de 1980 (DOMINGUES; BERMANN, 2012), a soja avança para o Norte, a região de maior índice de crescimento de área agrícola no País (FREITAS; MENDONÇA; LOPES, 2014). 
A expansão do cultivo de grãos para regiões carentes em infraestrutura intensifica as pressões por obras viárias. Segundo Frishtak (2008), para o Brasil alcançar o patamar logístico de países como China e Coreia do Sul seria necessário investir entre 4\% e 6\% do PIB durante vinte anos. Em transportes, o Brasil investiu 0,6\% do PIB em 2013, enquanto países emergentes, como Rússia, Índia, China, Coreia do Sul, Vietnã, Chile e Colômbia, na média, estão investindo 3,4\% do PIB (CAMPOS NETO, 2014).

O Movimento Pró-Logística ${ }^{1}$ vem desenvolvendo, com sucesso ${ }^{2}$, lobby por obras que viabilizem o escoamento pelos portos do Norte/Nordeste do País Santarém, Itacoatiara, Salvador ou São Luís - reduzindo os custos do frete marítimo em função da maior proximidade com os Estados Unidos, a Europa e o Canal do Panamá (passagem para as cargas rumo a China). Segundo o PróLogística, a priorização de obras de infraestrutura viária na porção norte do Brasil se justifica, já que, em 2013, 54,1\% do milho e da soja do País foram produzidos ao norte do Paralelo $16 \mathrm{~S}$ (abrangendo os estados do Mato Grosso, Tocantins, Goiás, Bahia, Maranhão e Pará). Entretanto, a maior parcela das exportações $(86,7 \%)$ foi realizada pelos portos do Sul e Sudeste (Santos, Paranaguá, Vitória, São Francisco do Sul), e somente 13,3\% pelo Norte/Nordeste (Porto Velho, Itacoatiara, Santarém, São Luís).

${ }^{1}$ Criado em agosto de 2009 para articular a implantação e manutenção da infraestrutura de logística federal e estadual em Mato Grosso. Presidido pela Associação dos Produtores de Soja e Milho (APROSOJA), é composto ainda pela Associação Mato-Grossense dos Produtores de Algodão (AMPA), Associação dos Criadores de Mato Grosso (ACRIMAT), Organização das Cooperativas Brasileiras em Mato Grosso - (OCB/MT), Federação da Agricultura e Pecuária de Mato Grosso (FAMATO), Federação das Indústrias no Estado de Mato Grosso (FIEMT), pelo Sistema Federação do Comércio de Bens, Serviços e Turismo do Estado de Mato Grosso (FECOMÉRCIO/MT), pelo Conselho Regional de Engenharia e Agronomia de Mato Grosso (CREA/MT), pela Associação Mato-grossense dos Municípios (AMM) e pelo Instituto Ação Verde. Elegeu projetos prioritários para Mato Grosso: as Hidrovias: Teles Pires-Tapajós, Arinos Juruena-Tapajós, Paraguai-Paraná e Araguaia-Tocantins. As Ferrovias: FICO (Ferrovia de Integração Centro Oeste) e Ferronorte (Rondonópolis-Santarém). As Rodovias: conclusão da BR163 e BR-158, implantação da BR-080 (Ribeirão Cascalheira- Luiz Alves/GO), da BR-242 (Sorriso, BR 163 - Ribeirão Cascalheira, BR 158) e BR 174, entre Castanheira e Colniza. Tratase na atualidade do mais influente porta-voz das tradings agrícolas.

${ }^{2}$ Um exemplo recente dos investimentos em obras no interior do bioma amazônico, fruto do lobby das tradings agrícolas, é o projeto de construção do trecho ferroviário entre os municípios de Sinop, em Mato Grosso, e Miritituba, no Pará, por parte das tradings Cargill, Bunge, Louis Dreyfus Commodities e Amaggi, consorciadas com a empresa de estruturação de negócios EDLP, que entregaram ao governo federal Proposta de Manifestação de Interesse (PMI). "Com custo estimado em R $\$ 11,5$ bilhões, 70\% financiado pelo BNDES, o trecho de 930 quilômetros terá capacidade para escoar 30 milhões de toneladas de grãos (soja e milho) por ano de Mato Grosso aos portos do Norte. Para o agronegócio, [...] a redução estimada do frete chega a 40\%, a depender das condições do mercado." (Valor Econômico, 5 nov. 2015). 
Ilustração 1 Produção e exportação de soja e milho, 2013

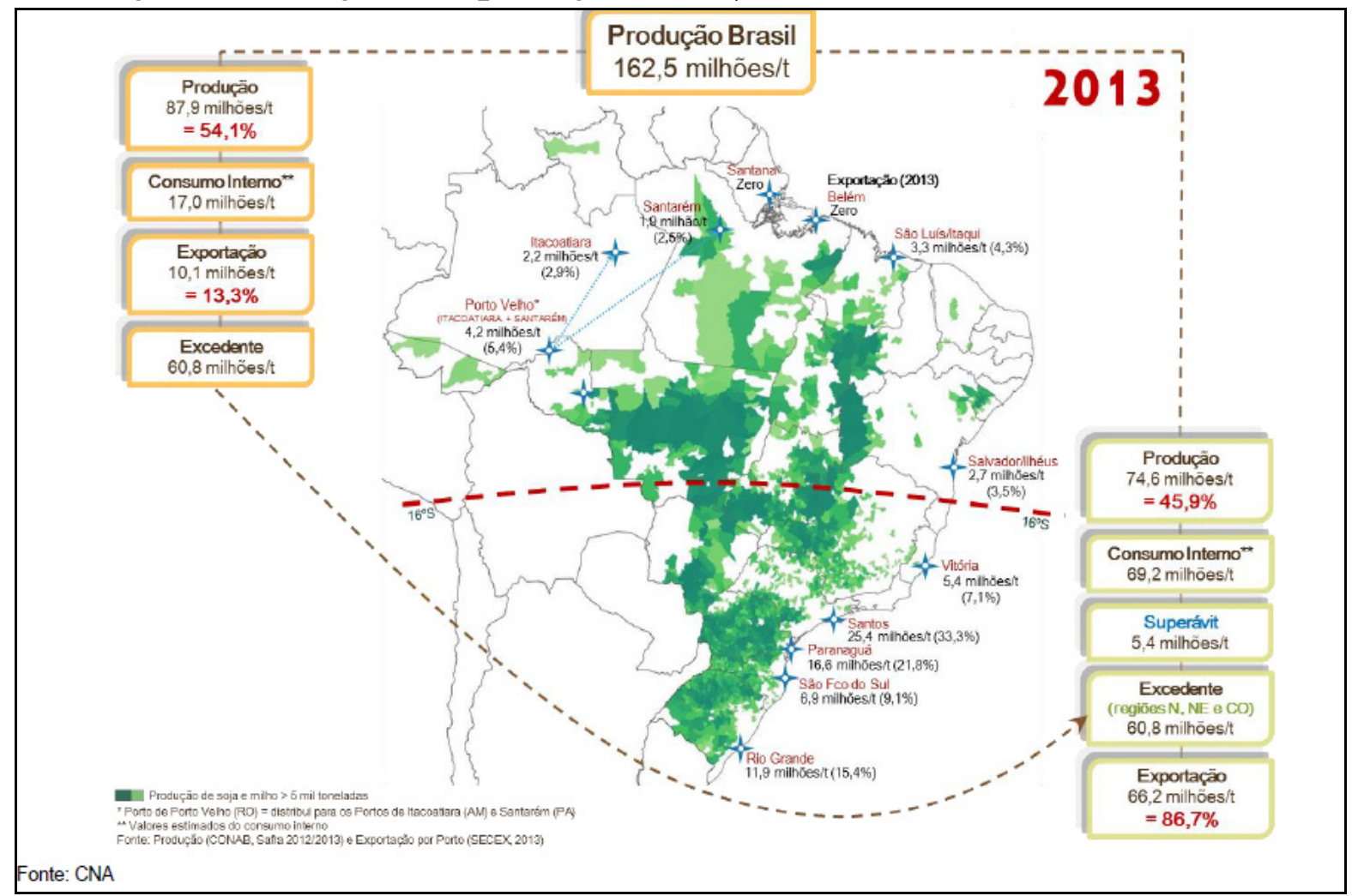

Fonte: CNA (2013).

O problema é que o avanço das obras de infraestrutura viária na região amazônica cria estímulos à progressão das monoculturas no interior do bioma, gerando fortes e perigosos impactos ambientais. A soja, especificamente, exige um cultivo intensivo com demanda elevada de recursos, principalmente energia, água, agrotóxicos e solo (WWF, 2014).

Pesquisas do ciclo de vida da produção da soja no Cerrado brasileiro encontraram importantes perdas anuais de erosão do solo, compostas de perda de matéria orgânica, compactação e acidificação (MATTSSON et al., 2000). Quanto à pressão sobre o recurso água, pesquisas em Querência no Mato Grosso (município que concentrou 31\% de toda a produção de soja da mesorregião Nordeste Matogrossense em 2010) identificaram menor disponibilidade de água no solo em lavouras de soja comparativamente a áreas de floresta (BASE et al., 2012). O dano ambiental causado pelos agrotóxicos, abrangendo a contaminação do solo, da água e a ameaça à biodiversidade, está amplamente difundido. Segundo o IBGE, estima-se que 35\% de todos os pesticidas utilizados no Brasil são usados em plantações de soja (WWF, 2014).

Evidencia-se, portanto, que as monoculturas agrícolas, e a soja em especial, geram fortes impactos ambientais. Trata-se de investigar se existem ganhos do ponto de vista do desenvolvimento regional. Formulado de outra maneira, há que investigar 
os impactos da expansão das monoculturas agrícolas sobre o desenvolvimento regional, e, ainda, se os pesados investimentos em infraestrutura viária necessários para viabilizar o escoamento da produção pela região Norte se justificam do ponto de vista dos ganhos para o conjunto da sociedade.

Neste sentido, este estudo pesquisou indicadores de desenvolvimento regional da mesorregião Nordeste Mato-grossense, cortada pela BR 158, vetor de expansão da soja a partir da década de 1980, e que foi contemplada recentemente por investimentos de recuperação e pavimentação da rodovia na ordem de $\mathrm{R} \$ 800$ milhões (BRASIL, PAC II, 2014) ${ }^{3}$. Com a conclusão do asfaltamento até a divisa do Pará ${ }^{4}$ a rodovia é hoje um dos vetores de expansão da soja para o interior do bioma amazônico.

A mesorregião Nordeste Mato-grossense era conhecida como Vale dos Esquecidos em função dos sofríveis indicadores sociais e do histórico de abandono por parte do governo estadual. Após a expansão das lavouras de soja na região, na década de 2000, passou a integrar a classificação de região dinâmica segundo o Ministério de Integração Nacional (2012).

3 A pesquisa integra projeto conjunto do Instituto de Estudos Sociais e Ambientais da Universidade Federal de Goiás, Instituto de Economia da Universidade Estadual de Campinas e Mestrado em Desenvolvimento e Planejamento Territorial da Pontifícia Universidade Católica de Goiás. O objetivo central é a avaliação dos impactos econômicos, sociais e ambientais das transformações produtivas na área do cerrado brasileiro derivados das obras de infraestrutura de ferrovias e rodovias.

${ }^{4}$ Permaneceu inconcluso apenas o trecho que originalmente atravessava a área indígena de Maraiwat sede, cujo traçado foi modificado por ordem judicial. 


\section{Ilustração 2 Mesorregião nordeste mato-grossense, 2015}

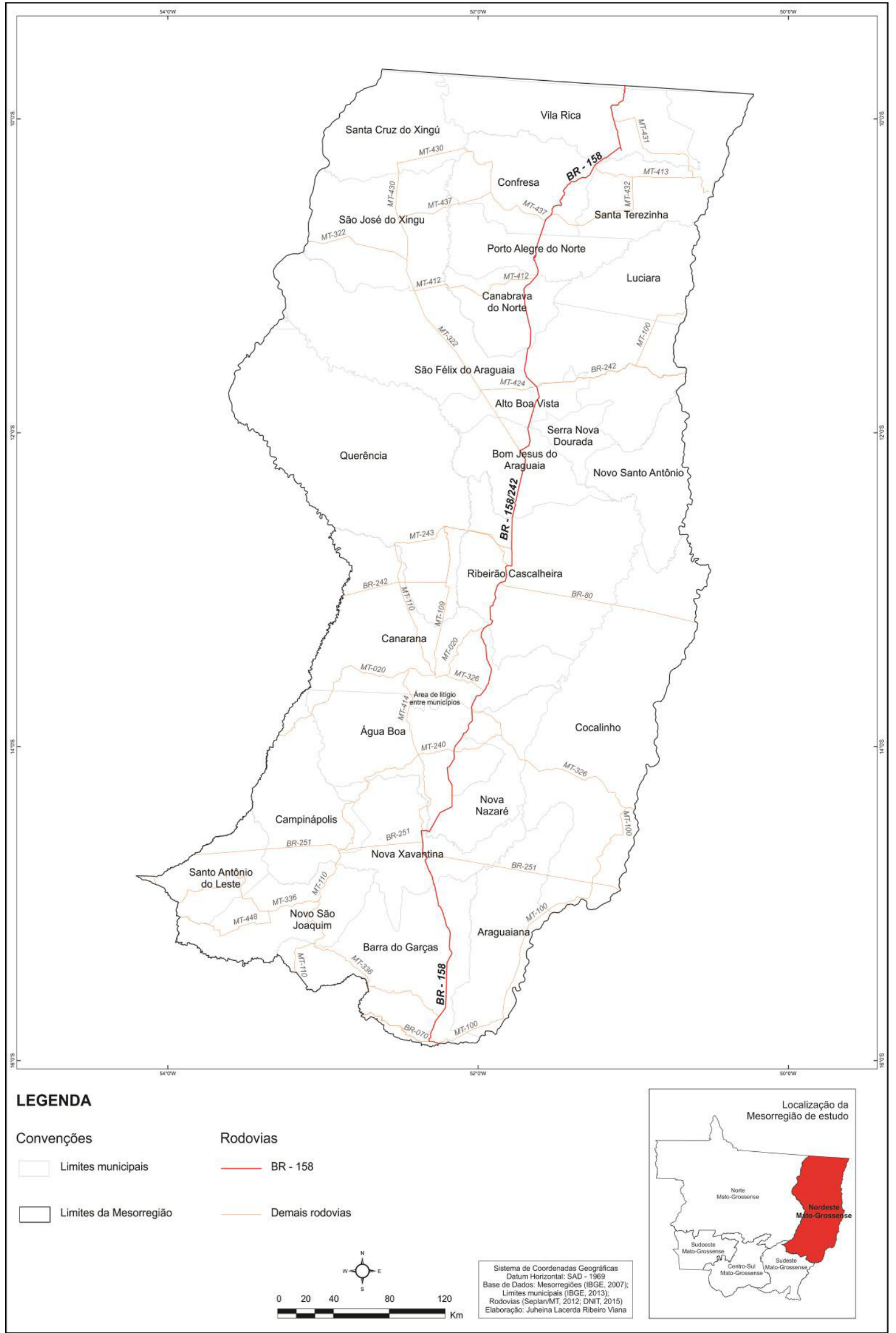

140 | Revista Brasileira de Desenvolvimento Regional, Blumenau, 3 (2), P. 135-159, Primavera de 2015 
A pesquisa reuniu dados da mesorregião referentes à produção e área plantada de produtos agrícolas, em especial da soja; Produto Interno Bruto, PIB; Valor Agregado; emprego; concentração de renda; renda domiciliar per capita (total e por quintis) e taxas de pobreza. Para melhor avaliar o impacto da expansão da produção de soja sobre o desenvolvimento regional foram selecionados indicadores dos municípios maiores produtores de grãos, Querência, Canarana e Água Boa, que concentravam $51 \%$ da área plantada de soja na mesorregião no ano de $2010^{5}$. Para os indicadores de demografia, taxas de pobreza e renda, confrontaram-se os dados dos municípios grandes produtores de soja com municípios do mesmo porte, com baixa ou nenhuma produção de soja, especificamente, Confresa, Porto Alegre do Norte e Vila Rica ${ }^{6}$.

Concluiu-se que o exponencial crescimento da produção agrícola impactou, sim, em crescimento econômico acima da média do estado e também do País, entretanto, não houve avanço nos aspectos renda e redução da pobreza e identificou-se importante defasagem de renda domiciliar per capita em relação às médias estaduais e nacionais. As taxas de pobreza, com destaque para a pobreza rural, são superiores às médias do estado, e em alguns municípios alcança níveis superiores a 50\%. O indicador Gini de concentração de renda teve uma evolução positiva, entretanto, a pesquisa por quintis de renda revelou que a desconcentração resultou estagnação relativa da renda do quinto mais rico. Não se identificou avanço significativo por parte dos estratos de renda mais pobres, tanto na comparação com as médias do estado, como do País.

Nos grandes municípios produtores de soja ocorreu melhora na renda domiciliar per capita entre 1991 e 2010, sobretudo por parte dos estratos mais pobres de renda. Já nos municípios não produtores de soja, a defasagem de renda em relação às médias do estado e do País manteve-se constante, ocorrendo em 2010 aumento da defasagem da renda do quinto mais pobre.

Identificou-se assim um aprofundamento da heterogeneidade intra-regional, tanto setorial, com simultâneo retrocesso da indústria e forte expansão do comércio e serviços, como social, com agravamento da pobreza nos municípios não produtores de soja.

Expõem-se a seguir os resultados da pesquisa.

\footnotetext{
${ }^{5}$ Tomou-se o ano de 2010 como referência, em função da utilização da base de dados dos Censos 1991, 2000 e 2010 para os indicadores de pobreza e renda.

${ }^{6}$ A base de dados foi extraída do IBGE (Produção Agrícola Municipal, Produto Interno Bruto dos Municípios, Censo Agropecuário, Censos Demográficos), Cadastro Geral de Empregados e Desempregados (CAGED), Ministério de Desenvolvimento Social e Combate à Fome (MDS) e Atlas do Desenvolvimento Humano no Brasil, 2013. Os valores da renda domiciliar per capita da mesorregião foram calculados a partir da média ponderada dos vinte e cinco municípios que a compõem.
} 


\section{Concentração fundiária}

O processo de ocupação de Mato Grosso foi marcado pela transferência de terras devolutas do Estado para a propriedade privada, resultando na formação de grandes latifúndios. As monoculturas de grãos em vastas extensões de terras têm origem nesta política (CAVALCANTE; MANÇANO, 2006). Segundo o Censo 2006, o índice Gini de concentração de terras no estado é de 0,8160, superior à média, tanto da Região Centro-Oeste (0,7920), como do Brasil $(0,8116)$ (PEREIRA, 2012, p. 80).

\section{Produção agrícola}

O avanço da soja na mesorregião deu-se a partir da expansão da área total destinada à agricultura, mas ocorreu também a substituição de culturas. Entre 1990 e 2000, a área destinada a lavouras temporárias passou de 309.259 para 381.650 hectares, um aumento de 23\%. Em 2010 a expansão da área plantada acelerou-se, atingindo a marca de 967.752 hectares, crescimento de $153 \%$ ao longo da década. Para termos uma dimensão da velocidade de expansão das lavouras, os dados de 2014 indicam nova aceleração, incremento de 109\% de área plantada entre 2010 e 2014, atingindo 2.029.510, hectares. A expansão da área de cultivo da soja é de 98\% (IBGE, Produção Agrícola Municipal).

A soja já era o principal produto agrícola em 1990, ocupando 47\% da área cultivada, avançando em 2010 para uma participação relativa de 76,6\%. A lavoura de arroz ocupava 36\% da área plantada em 1990, caindo para 5,73\% em 2010, e 1\% em 2014 (Gráfico 1). 
Gráfico 1 Lavouras temporárias: área plantada total; área plantada de soja e arroz (hectares), 1990-2014

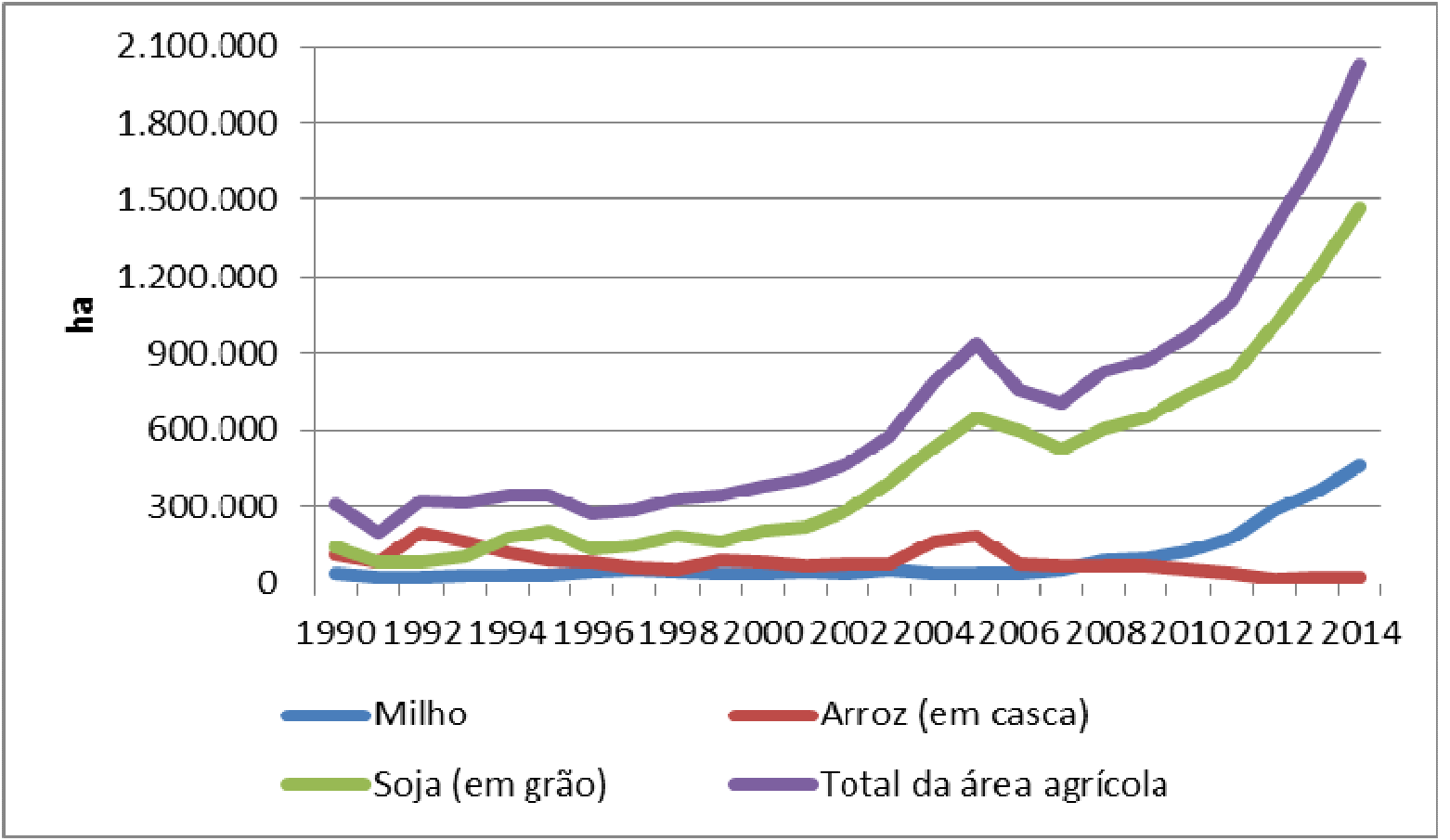

Fonte: IBGE, Produção Agrícola Municipal, 1990-2014.

Entre 2000 e 2014 as culturas com maior recuo em área plantada foram a cana de açúcar com 89\%, o arroz (73\%) e a mandioca (43\%) (IBGE, Produção Agrícola Municipal, 1990-2014). Referente à quantidade, a produção de soja na mesorregião expandiu em 266\% entre 2000 e 2010, taxa muito superior à do estado do Mato Grosso (114\%), e à do País (109\%) (Tabela 1).

Tabela 1 Produção de soja em grãos (toneladas), 2000 e 2010

\begin{tabular}{lrrc}
\hline \multicolumn{1}{c}{ Região } & 2000 & 2010 & \multicolumn{1}{c}{ Variação } \\
& & & $2000-2010$ \\
Nordeste mato-grossense & 630.140 & 2.310 .609 & $266 \%$ \\
Mato Grosso & 8.774 .470 & 18.787 .783 & $114 \%$ \\
Brasil & 32.820 .826 & 68.756 .343 & $109 \%$ \\
\hline
\end{tabular}

Fonte: IBGE, Produção Agrícola Municipal, 2000, 2010.

A área plantada de soja representava $54,17 \%$ da área agrícola total em 2000, avançando para 76,6\% em 2010. Quanto ao valor, em 2010 a produção de soja na mesorregião totalizou $\mathrm{R} \$ 1,19$ bilhões. 
Os dados do IBGE - Produção Agrícola Municipal, 2014 - apontam nova aceleração da expansão. Em apenas quatro anos, entre 2010 e 2014, a área plantada praticamente dobrou, com aumento de $98 \%$.

\section{Produção econômica}

Os dados referentes ao Produto Interno Bruto, PIB, indicam expansão econômica da mesorregião Nordeste Mato-grossense acima da média do estado e também do Brasil. Entre 2000 e 2010 a participação no PIB do estado do Mato Grosso foi ampliado em 0,04 ponto, passando de 7,24\% (2000) para 7,28\% (2010). Em relação ao País, a participação foi ampliada em 0,02 ponto, de 0,1\% (2000) para $0,12 \%(2010)$.

Tabela 2 Evolução da participação do PIB da mesorregião Nordeste Matogrossense no PIB do Mato Grosso e do Brasil, 2000 e 2010

\begin{tabular}{lcccc}
\hline \multirow{2}{*}{ PIB } & \multicolumn{2}{c}{2000} & \multicolumn{2}{c}{2010} \\
\cline { 2 - 5 } & $\begin{array}{c}\% \text { Mato } \\
\text { Grosso }\end{array}$ & $\%$ Brasil & $\%$ Mato Grosso & $\%$ Brasil \\
Total & 7,24 & 0,1 & 7,28 & 0,12 \\
\hline
\end{tabular}

Fonte: IBGE, Produto Interno Bruto, 2000, 2010.

A despeito do forte avanço das lavouras, ocorreu recuo da participação do VA Agropecuário, tanto no total da mesorregião, de 42,83\% (2000) para 35,38\% (2010), como no VA total do estado, de 3,25\% (2000) para 2,64\% (2010). A indústria reduziu sua participação no VA total do estado, de 0,89\% (2000) para 0,88\% (2010).

Já o setor de serviços ${ }^{7}$ ampliou sua participação no VA da mesorregião, avançando de $27,14 \%$ (2000) para 33,32\% (2010). Em relação ao estado, houve um avanço de 2,06\% (2000) para 2,49\% (2010) (Tabela 3).

\footnotetext{
${ }^{7}$ Exclusive administração, saúde e educação públicas e seguridade social.
} 
Tabela 3 VA total da mesorregião Nordeste Mato-grossense e do Mato Grosso, 2000 e 2010

\begin{tabular}{lcccc}
\hline \multirow{2}{*}{ Setor } & \multicolumn{2}{c}{2000} & \multicolumn{2}{c}{2010} \\
\cline { 2 - 5 } & $\begin{array}{c}\text { \% VA Total } \\
\text { Mesorregião }\end{array}$ & \% VA Total Grosso & \% VA Total & M VA Total \\
& 42,83 & 3,25 & 35,38 & 2,64 \\
VA agropecuário & 11,8 & 0,89 & 11,89 & 0,88 \\
VA indústria & 27,14 & 2,06 & 33,32 & 2,49 \\
VA serviços $^{1}$ & &
\end{tabular}

Fonte: IBGE, Produto Interno Bruto, 2000, 2010.

Analisando os indicadores macroeconômicos dos três maiores produtores de soja da mesorregião em 2010, por ordem de relevância, Querência, Canarana e Água Boa, verifica-se que a participação do VA de Querência no VA do estado do Mato Grosso avançou de 0,28\% (2000) para 0,65\% (2010); Canarana de 0,67\% (2000) recuou para 0,61\% (2010); e Água Boa cresceu de 0,6\% (2000) para 0,69\% (2010) e $0,72 \%$ (2012) (Tabela 4).

Tabela 4 Participação do VA bruto total de Querência, Canarana e Água Boano, 2000 e 2010

\begin{tabular}{ccccccc}
\hline \multirow{2}{*}{ Região } & \multicolumn{2}{c}{ Querência } & \multicolumn{2}{c}{ Canarana } & \multicolumn{2}{c}{ Água Boa } \\
\cline { 2 - 7 } & 2000 & 2010 & 2000 & 2010 & 2000 & 2010 \\
\% VA mesorregião & 3,7 & 8,7 & 8,7 & 8,1 & 8 & 9,2 \\
\% VA Mato Grosso & 0,28 & 0,65 & 0,67 & 0,61 & 0,6 & 0,69 \\
\hline
\end{tabular}

Fonte: IBGE, Produto Interno Bruto dos Municípios, 2000, 2010.

A aceleração da expansão do cultivo da soja entre 2010 e 2014, período no qual a produção e a área plantada dobraram, acentuou o ritmo de crescimento econômico da mesorregião, cuja participação no VA do Mato Grosso avançou de $7,48 \%$ (2010) para 8,01\% (2012). A mesma tendência é verificada em relação ao País, avanço da participação no VA total do Brasil, de 0,12\% (2010) para 0,16\% (2012) (IBGE, Produto Interno Bruto dos Municípios, 2010, 2012).

\section{Emprego}

Foram o comércio e os serviços que mais empregaram em 2010, com participação de $48 \%$ no total de empregos. Entre janeiro de 2003 e janeiro de 2010, estes 
setores ampliaram sua participação em 4 pontos porcentuais, gerando 2.943 empregos.

A agropecuária ocupou em janeiro de 2010 o segundo lugar no estoque total de empregos, participando com 33\%. Em termos absolutos, entre 2003 e 2010, a agropecuária contribuiu com geração de 3.458 empregos, ampliando a participação relativa em 3 pontos percentuais.

Chama atenção, no entanto, a perda de empregos no setor da indústria de transformação. Foram eliminados 2.133 postos de trabalho entre 2003 e 2010, provocando um recuo da participação relativa no estoque total de 20\% (2003) para 13\% (2010) (Tabela 5).

Tabela 5 Estoque de empregos por setores e porcentual sobre o total de empregos, mesorregião Nordeste Mato-grossense, 2003 e 2010

\begin{tabular}{lcccc}
\hline \multirow{2}{*}{ Setor } & \multicolumn{2}{c}{ Jan./2003 } & \multicolumn{2}{c}{ Jan./2010 } \\
\cline { 2 - 5 } Tompregos & $\begin{array}{c}\text { Participação no } \\
\text { total de } \\
\text { empregos }\end{array}$ & Empregos & $\begin{array}{c}\text { Participação no } \\
\text { total de } \\
\text { empregos }\end{array}$ \\
\hline Total & 34.652 & - & 38.327 & - \\
\hline Indústria & 7.017 & $20 \%$ & 4.884 & $13 \%$ \\
Agropecuário $_{\text {Serviços }}{ }^{1}$ & 10.250 & $30 \%$ & 12.775 & $33 \%$ \\
\hline
\end{tabular}

${ }^{1}$ Inclui: Comércio e serviços.

Fonte: MTE/CAGED, 2003, 2010.

As estatísticas de emprego dos três municípios grandes produtores de soja, Querência, Canarana e Água Boa para o período de 2003 a 2010 revelam prevalência do setor de comércio e serviços, que ampliou a participação no estoque total de empregos de 49,5\% (2003) para 51,9\% (2010). No período, a maior expansão de empregos deu-se na agropecuária, que ampliou a participação em 4 pontos, de 33\% (2003) para 36\% (2010). Também nos três municípios registra-se perda de empregos na indústria em 17\% (Tabela 6). 
Tabela 6 Variação do estoque de empregos por setores de municípios selecionados (Querência, Canarana e Água Boa ${ }^{1}$ ), 2003 e 2010

\begin{tabular}{lcccc}
\hline \multirow{2}{*}{ Setor } & \multicolumn{2}{c}{ Jan./2003 } & \multicolumn{2}{c}{ Jan./2010 } \\
\cline { 2 - 4 } Empregos & $\begin{array}{c}\text { Participação no } \\
\text { total de } \\
\text { empregos }\end{array}$ & Empregos & $\begin{array}{c}\text { Participação no } \\
\text { total de } \\
\text { empregos }\end{array}$ \\
Total & 7.937 & - & 10.269 & - \\
\hline Indústria & 1.125 & $11,7 \%$ & 962 & $9 \%$ \\
Agropecuária & 2.625 & $33,3 \%$ & 3.733 & $36,3 \%$ \\
Serviços & 3.935 & $49,5 \%$ & 5.338 & $51,9 \%$ \\
\hline
\end{tabular}

${ }^{1}$ Soma do estoque de empregos dos municípios.

Fonte: MTE/CAGED Estabelecimentos, 2003, 2010.

A aceleração da expansão do cultivo da soja após 2010 nos três municípios grandes produtores de soja acentua a expansão do setor de serviços em detrimento do setor agropecuário. $\mathrm{O}$ segmento serviços amplia a participação no estoque total de empregos de 51,9\% (2010) para 54,2\% (2014), enquanto a agropecuária recua de 36,3\% (2010) para 33,9\% (2014) (MTE/CAGED, 2010, 2014).

\section{Demografia}

No período compreendido entre 1991 e 2010 a população da mesorregião cresceu a uma taxa geométrica superior ao estado, 2,93\%, contra 2,47\% do Mato Grosso e 1,64\% do Brasil. De 2000 a 2010 a mesorregião cresceu 2,15\%, contra 2,05\% do Mato Grosso e 1,17\% do Brasil.

Quanto aos municípios grandes produtores de soja - Querência, Canarana e Água Boa - no período entre 1991 e 2010, a exceção de Água Boa, as taxas de expansão demográfica superaram as taxas da mesorregião e do estado. Há que apontar, porém, que a expansão demográfica acima das médias brasileiras não se deu exclusivamente em municípios de domínio do cultivo da soja; também municípios não produtores, a exemplo de Confresa, Porto Alegre do Norte e Vila Rica, de porte semelhante ao primeiro grupo, tiveram expansão superior à média. Em toda a mesorregião, o porcentual de população residente na área rural é alto, em média o dobro das taxas do estado do Mato Grosso e do Brasil (Tabela 7). 
Tabela 7 População residente, mesorregião Nordeste Mato-grossense e municípios selecionados, 1991 a 2010

\begin{tabular}{|c|c|c|c|c|c|c|}
\hline Região & 1991 & 2000 & $\begin{array}{l}\text { Variação } \\
1991-2000\end{array}$ & 2010 & $\begin{array}{l}\text { Variação } \\
\text { 2000-2010 }\end{array}$ & $\begin{array}{l}\text { \% população } \\
\text { rural } 2010\end{array}$ \\
\hline Brasil & 146.825 .475 & 169.799 .170 & $1,64 \%$ & 190.755 .799 & $1,17 \%$ & 15,64 \\
\hline Mato Grosso & 2.027 .231 & 2.504 .353 & $2,47 \%$ & 3.035 .122 & $2,05 \%$ & 18,2 \\
\hline Mesorregião & 177.999 & 227.659 & $2,93 \%$ & 276.901 & $2,15 \%$ & 32,23 \\
\hline Querência $^{8}$ & - & 7.274 & - & 13.033 & $7,74 \%$ & 54,18 \\
\hline Canarana & 11.909 & 15.408 & $3,09 \%$ & 18.754 & $2,15 \%$ & 21,06 \\
\hline Água Boa & 16.561 & 16.737 & $0,11 \%$ & 20.856 & $2,45 \%$ & 19,64 \\
\hline Confresa ${ }^{3}$ & - & 17.841 & - & 25.124 & $3,48 \%$ & 43,36 \\
\hline $\begin{array}{l}\text { Porto Alegre } \\
\text { do Norte }\end{array}$ & 10.151 & 8.623 & $-1,80 \%$ & 10.748 & $2,23 \%$ & 51,81 \\
\hline Vila Rica & 9.461 & 15.583 & $5,70 \%$ & 21.382 & $3,21 \%$ & 34,7 \\
\hline
\end{tabular}

Fonte: IBGE, Censo Demográfico 1991, 2000, 2010.

\section{Pobreza}

As estatísticas referentes às taxas de pobreza, concentração de renda e renda domiciliar per capita foram extraídas do banco de dados do Atlas do Desenvolvimento Humano no Brasil (2013), que remonta ao ano de $1991^{9}$, e do Panorama Municipal do Ministério de Desenvolvimento Social e Combate à Fome. Foram elaboradas médias ponderadas para a mesorregião a partir dos indicadores dos vinte e cinco municípios que a compõem.

Faz-se necessário contextualizar o perfil econômico da mesorregião em 1990. A pecuária de corte era a principal atividade econômica. A soja já era a cultura importante, mas o arroz ainda predominava. A área agrícola cultivada era de apenas 309.259 hectares. Para se ter noção da relevância da pecuária, em 2006 a área agrícola havia dobrado, alcançando 756.922 hectares, mas ainda era 8 vezes menor que a área de pastagens e os 5.957.309 hectares contabilizados pelo Censo Agropecuário (2006).

Em 1991 a taxa de pobreza na mesorregião era de 48,5\%, contra 35,5\% no estado de Mato Grosso (Brasil, 36,1\%). Em 2000, a taxa na mesorregião manteve-se

\footnotetext{
${ }^{8}$ Os municípios de Querência e Confresa ainda não haviam sido criados em 1991.

${ }^{9}$ Os valores são atualizados para os preços de agosto de 2010.
} 
estável em 35,6\% contra 22\% no estado (Brasil, 27,9\%). Em 2010 a taxa da mesorregião havia caído para 20\%, o dobro da média do estado de 10,5\% (Brasil, $15,2 \%)$.

São significativas as taxas de extrema pobreza rural em toda a mesorregião, perfazendo 19,3\% em 2010 (Mato Grosso, 14,8\%). Nos municípios selecionados grandes produtores de soja é também significativa a extrema pobreza rural (média de $15,5 \%$ ), ligeiramente superior à taxa de municípios não produtores abordados na pesquisa (média de 13,9\%) (Tabela 8).

Tabela 8 Taxas de pobreza total e extrema pobreza rural, 1991 a $2010^{1}$

\begin{tabular}{lcccc}
\hline \multirow{2}{*}{ Região } & \multicolumn{3}{c}{ Taxa de pobreza } & $\begin{array}{c}\text { Extrema pobreza } \\
\text { rural }\end{array}$ \\
\cline { 2 - 5 } Brasil & 1991 & 2000 & 2010 & 2010 \\
Mato Grosso & $36,1 \%$ & $27,9 \%$ & $15,2 \%$ & $23,52 \%$ \\
Nordeste Mato-grossense & $48,5 \%$ & $35,6 \%$ & $20 \%$ & $14,8 \%$ \\
Querência & - & $25,9 \%$ & $13,2 \%$ & $19,3 \%$ \\
Canarana & $35,5 \%$ & $17,7 \%$ & $10,3 \%$ & $19,5 \%$ \\
Água Boa & $37,9 \%$ & $21,1 \%$ & $7,4 \%$ & $21,0 \%$ \\
Confresa & - & $42,5 \%$ & $25,7 \%$ & $6,2 \%$ \\
Porto Alegre do Norte & $63,7 \%$ & $40,6 \%$ & $22,6 \%$ & $18,3 \%$ \\
Vila Rica & $53,9 \%$ & $34,8 \%$ & $13,6 \%$ & $16,3 \%$ \\
\hline
\end{tabular}

${ }^{1}$ Valores de 1991 e 2000 atualizados para agosto de 2010.

Fonte: Taxas de pobreza 1991, 2000, 2010: Atlas do Desenvolvimento Humano no Brasil, 2013. Taxas de extrema pobreza rural (municípios, estado e mesorregião): Ministério do Desenvolvimento Social e Combate à Fome, MDS, Panorama Municipal, 2015. Taxa de extrema pobreza rural do Brasil: MDS (2012).

\section{Renda domiciliar per capita}

Seguindo a tendência apontada pelas taxas de pobreza, sistematicamente superiores às taxas do estado no período de 1991 a 2010 (à exceção de Água Boa para o ano de 2010), os valores da renda domiciliar per capita encontram-se sistematicamente inferiores às médias do estado e do País. Em relação ao estado, a 
defasagem manteve-se praticamente constante: 29\% (1991) e 30\% (2010). Em relação ao País, a defasagem reduziu-se de 37\% (1991) para 33\% (2010), um nível ainda muito alto para uma região em franca expansão econômica (Tabela 9).

Tabela 9 Renda domiciliar per capita (R\$) e razão de renda domiciliar per capita da mesorregião Nordeste Mato-Grossense em relação ao estado do Mato Grosso e do Brasil, 1991 a $2010^{1}$

\begin{tabular}{|c|c|c|c|c|c|c|c|c|c|}
\hline \multirow[b]{2}{*}{ Região } & \multicolumn{3}{|c|}{1991} & \multicolumn{3}{|c|}{2000} & \multicolumn{3}{|c|}{2010} \\
\hline & Valor & $\begin{array}{c}\text { Razão } \\
\text { região/ } \\
\text { Mato } \\
\text { Grosso }\end{array}$ & $\begin{array}{r}\text { Razão } \\
\text { região/ } \\
\text { Brasil }\end{array}$ & Valor & $\begin{array}{c}\text { Razão } \\
\text { região/ } \\
\text { Mato } \\
\text { Grosso }\end{array}$ & $\begin{array}{l}\text { Razão } \\
\text { região/ } \\
\text { Brasil }\end{array}$ & Valor & $\begin{array}{c}\text { Razão } \\
\text { região/ } \\
\text { Mato } \\
\text { Grosso }\end{array}$ & $\begin{array}{r}\text { Razão } \\
\text { região/ } \\
\text { Brasil }\end{array}$ \\
\hline Brasil & 447,56 & - & - & 592,46 & - & - & 793,87 & - & - \\
\hline Mato Grosso & 395,34 & - & - & 582,62 & - & - & 762,52 & - & - \\
\hline Mesorregião & 282,23 & $71 \%$ & $63 \%$ & 407,19 & $69 \%$ & $69 \%$ & 533,90 & $70 \%$ & $67 \%$ \\
\hline
\end{tabular}

${ }^{1}$ Valores de 1991 e 2000 atualizados para agosto de 2010.

Fonte: Atlas do Desenvolvimento Humano no Brasil, 2013.

Quanto aos municípios grandes produtores de soja, os valores da renda domiciliar per capita são superiores às médias tanto da mesorregião, como do estado, entretanto, não é possível relacionar este fato à presença da cultura de soja. Os indicadores de renda domiciliar já superavam as médias estaduais em 1991, quando o cultivo do arroz era maior do que o cultivo da soja.

Os municípios que não têm o cultivo da soja como atividade econômica importante apresentam importante defasagem de renda, tanto em relação à mesorregião, como em relação ao estado e ao País. Defasagem próxima às médias do Nordeste.

Todos os municípios selecionados apontam evolução positiva no período, entretanto, há que ressaltar que os valores em 2010 não alcançam às médias nacionais (Tabela 10). 
Tabela 10 Tenda domiciliar per capita ( $R \$)$ e razão da renda da renda domiciliar per capita de municípios selecionados em relação à renda domiciliar per capita do Brasil, 1991 a $2010^{1}$

\begin{tabular}{|c|c|c|c|c|c|c|}
\hline Região & $\begin{array}{l}\text { Valor } \\
1991\end{array}$ & $\begin{array}{c}\text { Razão } \\
\text { município } \\
\text { (região) / } \\
\text { Brasil }\end{array}$ & $\begin{array}{l}\text { Valor } \\
2000\end{array}$ & $\begin{array}{l}\text { Razão } \\
\text { município } \\
\text { (região) / } \\
\text { Brasil }\end{array}$ & $\begin{array}{l}\text { Valor } \\
2010\end{array}$ & $\begin{array}{c}\text { Razão } \\
\text { município } \\
\text { (região) / } \\
\text { Brasil }\end{array}$ \\
\hline Brasil & 447,56 & - & 592,46 & - & 793,87 & - \\
\hline Mato Grosso & 395,34 & - & 582,62 & - & 762,52 & - \\
\hline Mesorregião & 282,23 & $63 \%$ & 407,19 & $69 \%$ & 533,90 & $67 \%$ \\
\hline Querência & - & - & 489,58 & $83 \%$ & 628,89 & $79 \%$ \\
\hline Canarana & 444,33 & $99 \%$ & 598,73 & $101 \%$ & 774,65 & $98 \%$ \\
\hline Água Boa & 371,2 & $83 \%$ & 695,97 & $117 \%$ & 720,74 & $91 \%$ \\
\hline Confresa & - & - & 323,27 & $55 \%$ & 484,89 & $61 \%$ \\
\hline $\begin{array}{l}\text { Porto Alegre do } \\
\text { Norte }\end{array}$ & 156,58 & $35 \%$ & 416,44 & $70 \%$ & 449,50 & $57 \%$ \\
\hline Vila Rica & 362,68 & $81 \%$ & 367,23 & $62 \%$ & 658,27 & $83 \%$ \\
\hline
\end{tabular}

${ }^{1}$ Valores de 1991 e 2000 atualizados para agosto de 2010.

Fonte: Atlas do Desenvolvimento Humano no Brasil, 2013.

Chama atenção que no ano de 2000 houve acentuada melhora da renda domiciliar per capita nos municípios de Canarana e Água Boa, com valores superiores às médias estaduais e nacionais. Por motivos a serem investigados ainda, em 2010 os dados indicam piora relativa da renda, que passa a situar-se abaixo das médias estaduais e nacionais.

Concentração de renda e renda domiciliar per capita por estratos: heterogeneidade intra-regional

O indicador Gini de concentração de renda é, aparentemente, favorável, evoluindo de 0,6 em 1991 (Mato Grosso, 0,6) para 0,5 em 2010 (Mato Grosso, 0,55). Entretanto, uma análise mais detalhada da evolução da renda domiciliar per capita por estratos revela que a redução da desigualdade resultou da estagnação relativa da renda do quinto mais rico. Os $1^{\circ}, 2^{\circ}, 3^{\circ}$ e $4^{\circ}$ quintis mais pobres avançaram discretamente entre 1991 e 2010, mas seguiram ainda em patamar muito inferior às médias estaduais (Tabela 11). 
Tabela 11 Renda per capita domiciliar (R\$) por quintis e razão da renda per capita domiciliar por quintis da mesorregião Nordeste Mato-Grossense em relação aos valores do Mato Grosso, 1991 a $2010^{1}$

\begin{tabular}{ccccccccccc}
\hline \multirow{2}{*}{ Quintil } & \multicolumn{3}{c}{1991} & \multicolumn{3}{c}{2000} \\
$\begin{array}{c}\text { Valor } \\
\text { Mesor- } \\
\text { região }\end{array}$ & $\begin{array}{c}\text { Valor } \\
\text { Mato } \\
\text { Grosso }\end{array}$ & $\begin{array}{c}\text { Razão } \\
\text { região / } \\
\text { Mato } \\
\text { Grosso }\end{array}$ & $\begin{array}{c}\text { Valor } \\
\text { Mesor- } \\
\text { região }\end{array}$ & $\begin{array}{c}\text { Valor } \\
\text { Mato } \\
\text { Grosso }\end{array}$ & $\begin{array}{c}\text { Razão } \\
\text { região / } \\
\text { Mato } \\
\text { Grosso }\end{array}$ & $\begin{array}{c}\text { Valor } \\
\text { Mesor- } \\
\text { região }\end{array}$ & $\begin{array}{c}\text { Valor } \\
\text { Mato }\end{array}$ & $\begin{array}{c}\text { Razão } \\
\text { região / } \\
\text { Mato } \\
\text { Grosso }\end{array}$ \\
$1^{\circ}$ Quintil & 34,00 & 53,00 & $64 \%$ & 41,00 & 74,00 & $55 \%$ & 77,00 & 123,00 & $63 \%$ \\
$2^{\circ}$ Quintil & 83,00 & 120,00 & $69 \%$ & 117,00 & 173,00 & $68 \%$ & 203,00 & 284,00 & $71 \%$ \\
$3^{\circ}$ Quintil & 141,00 & 197,00 & $71 \%$ & 192,00 & 275,00 & $70 \%$ & 328,00 & 444,00 & $74 \%$ \\
$4^{\circ}$ Quintil & 241,00 & 338,00 & $71 \%$ & 314,00 & 457,00 & $69 \%$ & 513,00 & 689,00 & $74 \%$ \\
$5^{\circ}$ Quintil & 809,00 & 1269,00 & $64 \%$ & 1181,00 & 1934,00 & $61 \%$ & 1466,00 & 2271,00 & $64 \%$ \\
\hline
\end{tabular}

${ }^{1}$ Valores de 1991 e 2000 atualizados para agosto de 2010.

Fonte: Atlas do Desenvolvimento Humano no Brasil, 2013.

A renda domiciliar per capita por quintis da mesorregião na comparação com os valores do País tem evolução positiva com redução do hiato em todos os estratos no período analisado, entretanto, mantém-se ainda em níveis altos no ano de 2010 (Tabela 12).

Tabela 12 Renda per capita domiciliar (R\$) por quintis e razão da renda per capita domiciliar por quintis da mesorregião Nordeste Mato-Grossense em relação aos valores do Brasil, 1991 a $2010^{1}$

\begin{tabular}{ccccccccccc}
\hline \multirow{2}{*}{ Quintil } & \multicolumn{3}{c}{1991} & \multicolumn{3}{c}{2000} \\
\cline { 2 - 10 } & $\begin{array}{c}\text { Valor } \\
\text { Mesor- } \\
\text { região }\end{array}$ & $\begin{array}{c}\text { Valor } \\
\text { Brasil }\end{array}$ & $\begin{array}{c}\text { Razão } \\
\text { região/ } \\
\text { Brasil }\end{array}$ & $\begin{array}{c}\text { Valor } \\
\text { Mesor- } \\
\text { região }\end{array}$ & $\begin{array}{c}\text { Valor } \\
\text { Brasil }\end{array}$ & $\begin{array}{c}\text { Razão } \\
\text { região/ } \\
\text { Brasil }\end{array}$ & $\begin{array}{c}\text { Valor } \\
\text { Mesor- } \\
\text { região }\end{array}$ & $\begin{array}{c}\text { Valor } \\
\text { Brasil }\end{array}$ & $\begin{array}{c}\text { Razão } \\
\text { região/ } \\
\text { Brasil }\end{array}$ \\
$1^{\circ}$ Quintil & 34,00 & 43,00 & $79 \%$ & 41,00 & 54,00 & $75 \%$ & 77,00 & 96,00 & $80 \%$ \\
$2^{\circ}$ Quintil & 83,00 & 107,00 & $77 \%$ & 117,00 & 149,00 & $79 \%$ & 203,00 & 454,00 & $82 \%$ \\
$3^{\circ}$ Quintil & 141,00 & 201,00 & $70 \%$ & 192,00 & 268,00 & $72 \%$ & 328,00 & 422,00 & $78 \%$ \\
$4^{\circ}$ Quintil & 241,00 & 383,00 & $63 \%$ & 314,00 & 490,00 & $64 \%$ & 513,00 & 689,00 & $74 \%$ \\
$5^{\circ}$ Quintil & 809,00 & $1.504,00$ & $54 \%$ & $1.181,00$ & $2.001,00$ & $59 \%$ & $1.466,00$ & $2.530,00$ & $58 \%$ \\
\hline
\end{tabular}

${ }^{1}$ Valores de 1991 e 2000 atualizados para agosto de 2010.

Fonte: Atlas do Desenvolvimento Humano no Brasil, 2013. 
Nos municípios grandes produtores de soja identifica-se acentuada evolução positiva da renda per capita domiciliar por parte do $1^{\circ}, 2^{\circ}$ e $3^{\circ}$ quintis mais pobres, que ultrapassam em 2010 tanto as médias do estado, como do País (Tabela 13).

Tabela 13 Renda per capita domiciliar (R\$) por quintis e razão da renda per capita domiciliar por quintis dos municípios Querência, Canarana, Água $\mathrm{Boa}^{1}$ em relação aos valores do Mato Grosso e do Brasil, 1991 a $2010^{2}$

\begin{tabular}{|c|c|c|c|c|c|c|c|c|c|}
\hline & & 1991 & & & 2000 & & & 2010 & \\
\hline Quintil & Valor & $\begin{array}{c}\text { Razão } \\
\text { município } \\
\text { /Mato } \\
\text { Grosso }\end{array}$ & $\begin{array}{c}\text { Razão } \\
\text { município/ } \\
\text { Brasil }\end{array}$ & Valor & $\begin{array}{c}\text { Razão } \\
\text { município } \\
\text { /Mato } \\
\text { Grosso }\end{array}$ & $\begin{array}{c}\text { Razão } \\
\text { município } \\
\text { /Brasil }\end{array}$ & Valor & $\begin{array}{c}\text { Razão } \\
\text { município } \\
\text { /Mato } \\
\text { Grosso }\end{array}$ & $\begin{array}{c}\text { Razão } \\
\text { município } \\
\text { /Brasil }\end{array}$ \\
\hline $1^{\circ}$ Quintil & 42,00 & $84 \%$ & $98 \%$ & 61,00 & $82 \%$ & $112 \%$ & 127,00 & $103 \%$ & $132 \%$ \\
\hline $2^{\circ}$ Quintil & 101,00 & $93 \%$ & $94 \%$ & 167,00 & $97 \%$ & $112 \%$ & 299,00 & $105 \%$ & $122 \%$ \\
\hline $3^{\circ}$ Quintil & 184,00 & $102 \%$ & $91 \%$ & 270,00 & $98 \%$ & $101 \%$ & 457,00 & $102 \%$ & $108 \%$ \\
\hline $4^{\circ}$ Quintil & 346,00 & $94 \%$ & $90 \%$ & 434,00 & $95 \%$ & $88 \%$ & 683,00 & $99 \%$ & $99 \%$ \\
\hline $5^{\circ}$ Quintil & 1194,00 & $84 \%$ & $79 \%$ & 2040,00 & $105 \%$ & $102 \%$ & 1972,00 & $86 \%$ & $78 \%$ \\
\hline
\end{tabular}

${ }^{1}$ Valores de 1991 e 2000 atualizados para agosto de 2010.

Fonte: Atlas do Desenvolvimento Humano no Brasil, 2013.

Quanto aos municípios que ainda não cultivavam de forma importante a soja em 2010, identifica-se para 1991 e 2010 uma forte defasagem de renda, tanto em relação ao estado, como ao Brasil. A renda domiciliar per capita tem, em média, valores que representam metade das médias estaduais e nacionais, ocorrendo, em 2010, deterioração acentuada no quinto mais pobre, cujo valor passa a valer menos que um terço da média estadual e menos da metade da média nacional (Tabela 14).

Comparando os dois grupos de municípios, identifica-se um aumento do hiato de renda no $1^{\circ}, 2^{\circ}$ e $3^{\circ}$ quintil, que já era de dimensão importante em 1991, acentuando-se ainda mais em 2010. O valor da renda do quinto mais pobre nos municípios não produtores de soja em 2010 passou a representar apenas 31\%do valor da renda do quinto mais pobre no grupo de municípios grandes produtores de soja. Já nos estratos superiores de renda ( $4^{\circ}$ e $5^{\circ}$ quintil) ocorre redução da defasagem no período estudado (Tabela 15). 
Tabela 14 Renda per capita domiciliar (R\$) por quintis e razão da renda per capita domiciliar por quintis dos municípios Confresa, Porto alegre do Norte e Vila Rica ${ }^{1}$ em relação aos valores do Mato Grosso e do Brasil, 1991 a $2010^{2}$

\begin{tabular}{|c|c|c|c|c|c|c|c|c|c|}
\hline \multirow[b]{2}{*}{ Quintil } & \multicolumn{3}{|c|}{1991} & \multicolumn{3}{|c|}{2000} & \multicolumn{3}{|c|}{2010} \\
\hline & Valor & $\begin{array}{c}\text { Razão } \\
\text { município } \\
\text { /Mato } \\
\text { Grosso }\end{array}$ & $\begin{array}{c}\text { Razão } \\
\text { município } \\
\text { /Brasil }\end{array}$ & Valor & $\begin{array}{c}\text { Razão } \\
\text { município } \\
\text { /Mato } \\
\text { Grosso }\end{array}$ & $\begin{array}{c}\text { Razão } \\
\text { município } \\
\text { /Brasil }\end{array}$ & Valor & $\begin{array}{c}\text { Razão } \\
\text { município } \\
\text { /Mato } \\
\text { Grosso }\end{array}$ & $\begin{array}{c}\text { Razão } \\
\text { município } \\
\text { /Brasil }\end{array}$ \\
\hline $1^{\circ}$ Quintil & 23,00 & $43 \%$ & $53 \%$ & 35,00 & $47 \%$ & $64 \%$ & 40,00 & $32 \%$ & $42 \%$ \\
\hline $2^{\circ}$ Quintil & 57,00 & $47 \%$ & $53 \%$ & 107,00 & $62 \%$ & $72 \%$ & 133,00 & $47 \%$ & $54 \%$ \\
\hline $3^{\circ}$ Quintil & 102,00 & $52 \%$ & $51 \%$ & 182,00 & $66 \%$ & $68 \%$ & 231,00 & $52 \%$ & $55 \%$ \\
\hline $4^{\circ}$ Quintil & 192,00 & $57 \%$ & $50 \%$ & 311,00 & $68 \%$ & $63 \%$ & 397,00 & $57 \%$ & $57 \%$ \\
\hline $5^{\circ}$ Quintil & 746,00 & $59 \%$ & $50 \%$ & 1208,00 & $62 \%$ & $60 \%$ & 1357,00 & $60 \%$ & $54 \%$ \\
\hline
\end{tabular}

${ }^{1}$ Média ponderada dos valores de renda dos três municípios.

${ }^{2}$ Valores de 1991 e 2000 atualizados para agosto de 2010.

Fonte: Atlas do Desenvolvimento Humano no Brasil, 2013.

Tabela 15 Razão da renda domiciliar per capita por quintis entre os municípios Confresa, Porto Alegre do Norte, Vila Rica ${ }^{1}$ em relação a Querência, Canarana, Água Boa ${ }^{1}, 1991$ a $2010^{2}$

\begin{tabular}{rlll}
\hline Quintil & 1991 & 2000 & 2010 \\
$1^{\circ}$ Quintil & $55 \%$ & $57 \%$ & $31 \%$ \\
$2^{\circ}$ Quintil & $56 \%$ & $64 \%$ & $44 \%$ \\
$3^{\circ}$ Quintil & $55 \%$ & $67 \%$ & $50 \%$ \\
$4^{\circ}$ Quintil & $55 \%$ & $71 \%$ & $58 \%$ \\
$5^{\circ}$ Quintil & $62 \%$ & $59 \%$ & $68 \%$ \\
\hline
\end{tabular}

${ }^{1}$ Média ponderada dos valores dos três municípios.

${ }^{2}$ Valores de 1991 e 2000 atualizados para agosto de 2010.

Fonte: Atlas do Desenvolvimento Humano no Brasil, 2013.

Os dados indicam um quadro de aprofundamento da heterogeneidade de renda intra-regional. Enquanto os municípios grandes produtores de soja melhoraram os indicadores para 2010, os municípios não produtores permaneceram estagnados, ou mesmo retrocederam. Nesse sentido, a aparente constância dos valores da renda domiciliar per capita na mesorregião na comparação com os valores estaduais e nacionais ao longo do período estudado, mascara, na verdade, uma situação de crescente heterogeneidade entre os municípios. 


\section{O drama dos pequenos e médios produtores rurais e o aprofundamento da heterogeneidade intra-regional}

A pesquisa de indicadores regionais na mesorregião Nordeste Mato-grossense apontou que a grande riqueza gerada pela produção de soja - $\mathrm{R} \$ 1,19$ bilhão em 2010 - não foi capaz de disseminar-se de forma homogênea pelo território. Ao contrário, aumentou a disparidade entre os municípios, as taxas de pobreza seguiram altas, alargou-se a desigualdade entre os diferentes setores produtivos com importante retração da indústria, não ocorreu geração de empregos acima da média nacional e a defasagem de renda em relação às médias brasileiras em todos os estratos foi mantida constante ao longo de duas décadas.

Um Diagnóstico Rápido Participativo (DRP) junto a sindicatos, associações e organizações da sociedade civil em municípios selecionados na mesorregião ${ }^{10}$ indicou que esta situação decorre em larga medida da falta de opção de renda para pequenos e médios produtores rurais, que não têm capital suficiente para iniciar uma lavoura de soja. $\mathrm{Na}$ mesorregião, $70 \%$ dos estabelecimentos são da agricultura familiar, ocupando 8,8\% da área total (Censo Agropecuário, 2006). Levando em conta que $32 \%$ da população ainda reside na área rural, a inserção produtiva do pequeno produtor tem repercussão importante sobre $\mathrm{O}$ desenvolvimento regional.

A produção de hortifrutigranjeiros vem recuando sistematicamente e o abastecimento da região depende na quase totalidade das CEASA de Goiânia e Brasília. Os produtos viajam em média $800 \mathrm{~km}$ até chegar aos diferentes municípios da região. Considerando que $50 \%$ dos produtos comercializados no CEASA de Goiânia vêm de fora do estado, majoritariamente de São Paulo e Paraná, a mais de $1.000 \mathrm{~km}$ de distância (LIMA, 2015), configura-se uma situação absurda do ponto de vista da sustentabilidade: uma região exportadora de grãos e carne não logra produzir os alimentos consumidos pela população local, dependendo do abastecimento de produtos que viajam por mais de $1.000 \mathrm{~km}$ por estradas de má qualidade.

A produção de suínos e galináceos, tradicionalmente atividades do pequeno produtor, caiu em 50\% e 40\% respectivamente, no período entre 1990 e 2014 (Produção Pecuária Municipal, 1990-2014). Grande parcela de pequenos e médios produtores migrou para a produção leiteira, que conta com a vantagem da logística

\footnotetext{
${ }^{10}$ Junto a Sindicatos de Trabalhadores Rurais em Barra do Garças e Água Boa; Sindicato dos Trabalhadores na Indústria em Barra do Garças; Associação Comercial e Industrial em Canarana, no Instituto Socioambiental em Canarana, representante do IBAMA em Água Boa, entre outros.
} 
disponibilizada pelos laticínios ${ }^{11}$, entretanto, trata-se de atividade de baixa margem de lucro, conforme demonstrado para Goiás (GOMES, 2009; SILVA, 2013) e Mato Grosso (GOMES, 2012). Pesquisas para Goiás indicam que as margens da pecuária leiteira não são competitivas na comparação com outras atividades rurais (pecuária de corte ou produção de soja), tampouco com atividades urbanas, e não contribuem para alavancar a renda nas bacias leiteiras do estado (SILVA, 2013).

Para superar os impasses apontados, as associações explicitaram demandas por orientação técnica para viabilizar a diversificação da produção; adequação da legislação sanitária, permitindo assim beneficiamento da produção agropecuária por parte do pequeno produtor; investimentos na malha rodoviária municipal e suporte logístico para o armazenamento e a distribuição da produção na sede do município e/ou na região.

Quanto ao segmento industrial, o Diagnóstico Rápido Participativo apontou forte demanda por investimentos na malha rodoviária estadual, viabilizando assim um mercado regional. Foi informado que na ultima década houve muitas promessas, porém pouca concretização de obras nas rodovias estaduais e municipais do Vale do Araguaia Mato-grossense.

\section{Considerações finais}

Os resultados da pesquisa indicam que políticas regionais focadas em apenas um objetivo - expandir e ao mesmo tempo potencializar a competitividade de uma commodity agrícola destinada à exportação - tendem a aprofundar perigosamente heterogeneidades econômicas, sociais e setoriais. Concorda-se com Tânia Bacelar de Araújo quando aponta que "a dinâmica regional entregue apenas às próprias decisões do mercado, tende a exacerbar seu caráter seletivo, ampliando fraturas herdadas." (ARAÚJO apud BRANDÃO, 2007, p. 19-20).

A soja em grão é um produto central para a geração de divisas, liderando a pauta exportadora do país. Porém, os investimentos em obras de infraestrutura viária no interior do bioma amazônico, visando a abertura de corredores de exportação para o produto in natura, como quer o movimento Pró-Logística, não são justificáveis do ponto de vista dos passivos ambientais gerados e dos inexistentes ganhos no plano do desenvolvimento regional.

Alternativas à comercialização do grão in natura existem como aponta documento do Ministério da Integração Nacional (2012). Um conjunto de opções que agregam valor ao produto soja é elencado, como, por exemplo, o desenvolvimento

\footnotetext{
${ }^{11}$ A expansão da produção leiteira na mesorregião entre 1990 e 2014 segue as médias de expansão no estado e no País (produção Pecuária Municipal, 1990-2014).
} 
de indústria de máquinas e equipamentos próximos às regiões produtoras, bem como investimento em capacidades locais em serviços técnicos especializados. Sugere o documento ainda estímulos para a criação de empresas inovadoras, que incluem produtos orgânicos, alimentos funcionais, biocombustíveis, novos produtos da sucroquímica, especialidades da soja e outros (BRASIL, 2012, p. 56).

Conclui-se pela necessidade da diversificação de investimentos nas regiões consolidadas de plantio de soja. Estimular o beneficiamento da produção por meio da inovação, tanto a montante como a jusante da cadeia produtiva. No plano da infraestrutura viária, reduzir a pressão pela criação de corredores de exportação que adentrem o bioma amazônico, através da criação de alternativas à comercialização in natura. E ainda no plano de obras viárias, priorizar a ampliação e o melhoramento da malha estadual e municipal, viabilizando a diversificação de empreendimentos e opções de renda por parte de pequenos e médios produtores rurais e pequenos e médios empresários urbanos.

\section{Referências}

ARAÚJO, Tania Bacelar de. Prefácio in BRANDÃO, Carlos. Território \& Desenvolvimento. UNICAMP, Campinas, 2007.

BRASIL. Ministério de Desenvolvimento Social e Combate à Fome, MDS. Secretaria de Avaliação e Gestão da Informação. Estudo Técnico N ${ }^{\circ}$ 20/2012. Evolução da pobreza e da extrema pobreza - Comparação entre os Censos de 2000 e 2010. Brasília, 2012.

. Panorama Municipal, 2015.

. Ministério da Integração Nacional, MI. Documento de Referência da I

Conferência de Desenvolvimento Regional. Brasília, 2012.

- Ministério do Planejamento Orçamento e Gestão, PAC II, 2014. Rodovias concluídas Mato Grosso, BR 158. Disponível em: http://www.pac.gov.br/infraestrutura-logistica/rodovias/mt. Acesso em: 02 mar. 2015.

- Ministério do Trabalho e Emprego, MTE. Cadastro Geral De Empregados e Desempregados, CAGED Estabelecimentos. 2003-2010. 
CAMPOS NETO, Carlos Alvares da Silva. Investimentos na infraestrutura de transportes: avaliação do período 2002-2013 e perspectivas para 2014-2016. Brasília: IPEA Dezembro de 2014. (Texto para Discussão 2014). Disponível em: http://www.ipea.gov.br/portal/index.php?option=com content\&view=article\&i $\underline{\mathrm{d}=24236}$.

CAVALCANTE, Matuzalem; FERNANDES, Bernardo Mançano. Formação territorial, agronegócio e atuais mudanças na estrutura fundiária de Mato Grosso. Revista NERA, ano 9, n. 8. Presidente Prudente, jul./dez., 2006.

FREITAS, Rogério Edivaldo; MENDONÇA, Marco Aurélio Alves de; Geovane de Oliveira Lopes. Expansão de área agrícola: perfil e desigualdade entre as mesorregiões brasileiras. Brasília: IPEA, Janeiro 2014. (Texto para Discussão 1926). Disponível em: www.repositorio.ipea.gov.br/bitstream/11058/2658/1/ TD 1926.pdf.

FRISCHTAK, Cláudio Roberto. O investimento em infra-estrutura no Brasil: histórico recente e perspectivas. Pesquisa e Planejamento Econômico, v. 38, n. 2, agosto de 2008. Disponível em: http://ppe.ipea.gov.br/index.php/ppe/article/ view/1129.

PEREIRA, Benedito Dias. Agropecuária de Mato Grosso. Velhas questões de uma nova economia. EDUFMT, Cuiabá, 2012.

PNUD. Programa das Nações Unidas para e Desenvolvimento. Atlas do Desenvolvimento Humano no Brasil, 2013. Disponível em: http://www.atlasbrasil.org.br/2013/pt/download. Acesso em: 5 jul. 2015.

FIESP. Federação das Indústrias de São Paulo. Safra Mundial de Soja 2015/16 $5^{\circ}$ Levantamento do USDA. Informativo DEAGRO, São Paulo, setembro de 2015.

GOMES, Sebastião Teixeira. Diagnóstico da cadeia produtiva do leite em Goiás, 2008-2009. Goiânia, FAEG, 2009.

; Instituto Mato-Grossense de Economia Agropecuária (IMEA). Diagnóstico da cadeia produtiva do leite no estado de Mato Grosso. Relatório de pesquisa. Cuiabá, Famato, 2011.

IBGE. Instituto Brasileiro de Geografia e Estatística. Produção Agrícola Municipal, 1990 a 2014.

. Produto Interno Bruto, 2000, 2010, 2012. 
. Censo Agropecuário, 2006.

Censo Demográfico, 1991, 2000, 2010.

LIMA, Karla Kellem de. O planejamento e a gestão da Central de Abastecimento do Estado de Goiás - CEASA/GO. Dissertação (Mestrado), Mestrado em Desenvolvimento e Planejamento Territorial, PUCGoiás, Goiânia, 2015.

MATTSSON, Berit; CEDERBERG, Chistel; BLIX, Lisa. Agricultural land use in life cycle assessment (LCA): case studies of three vegetable oil crops. Journal of Cleaner Production, n. 8, p. 283-292. Göteborg, Suécia, 2000.

SILVA, Margot Riemann Costa e; ESTEVAM, Luis. O esvaziamento das regiões rurais? O caso da bacia leiteira de Piracanjuba - GO - Brasil (2000-2010). Redes, UNISC, v. 18, n. 3, 2013.

VALOR ECONÔMICO. Tradings se unem para construir o "ferrogrão". 5 nov. 2015. Disponível em: http://www.valor.com.br/agro/4302094/tradings-seunem-para-construir-ferrograo. Acesso em: 9 nov. 2015.

WWF. The growth of soy: impacts and solutions. (O crescimento da soja: impactos e soluções). WWF International (Secretariado Internacional da Rede WWF). Suíça: 2014. Disponível em: http://d3nehc6yl9qzo4.cloudfront.net/ downloads/wwf relatorio soja port.pdf. Acesso em: 07 jul. 2015.

Endereço para correspondência:

Margot Riemann Costa e Silva - margotriemann@gmail.com

Praça Universitária, Setor Universitário, 1.440

74.605-010 Goiânia/GO, Brasil

CarlosLeão-cleao17@gmail.com

Praça Universitária, Setor Universitário, 1.440

74.605-010 Goiânia/GO, Brasil

Rosenilda Maria de Morais Silva - rosenildaipora@yahoo.com.br

Praça Universitária, Setor Universitário, 1.440

74.605-010 Goiânia/GO, Brasil

Aline dos SantosSousa-adm_alinesousa@hotmail.com

Praça Universitária, Setor Universitário, 1.440

74.605-010 Goiânia/GO, Brasil 